\title{
Modèle prophétique et modèle de sainteté dans le soufisme ancien
}

Quelques exemples

\author{
Pierre Lory
}

Introduction

Que signifiait l'imitation du Prophète Muhammad pour les mystiques les plus anciens, au II $\mathrm{e} / \mathrm{VIII}^{\mathrm{e}}$ siècle ? Comment la vénération du Prophète a-t-elle été exprimée durant cette période initiale? Et comment cette conception a-t-elle évoluée? Ce modeste article voudrait apporter quelques éléments à un domaine de recherche déjà bien parcouru par les spécialistes. Les réponses dépendent bien sûr de la définition donnée au terme «mystique »-lui-même si discuté en langue française. Il est généralement admis que la mystique n'est pas l'équivalent d'une simple dévotion, même très intense. Elle ne s'identifie pas non plus à l'ascèse, même sévère. Beaucoup a été écrit sur la démarcation entre le renoncement dit zuhd, et la mystique correspondant au soufisme proprement dit ${ }^{1}$. On peut en tout cas aisément démarquer les œuvres sur le zuhd comme celles de Ibn al-Mubārak (m. 181/797) ou de Ibn Ḥanbal (m. 241/855) de la mystique soufie. En bref, posons la mystique comme une recherche expériencielle de la présence divine dès ici-bas. Ce qui modifie profondément le vécu religieux : la perspective eschatologique en particulier diffère de celle du croyant ordinaire. Si la présence miséricordieuse de Dieu est approchée dès ici-bas, l'éternité devient de quelque manière déjà présente ; même sans parler ici d'union mystique.

Quand et comment la mystique au sens strict est-elle apparue en islam? Était-elle présente dès les premières générations ? Clairement, il est impossible d'affirmer quoique ce soit en ce sens pour ce qui est du premier siècle, de la génération des Compagnons et des Suivants. La vaste littérature accumulée à ce sujet dépend de reconstitutions dues à des traditionnistes des générations ultérieures sur lesquelles l'historien n'a pas véritablement prise. Les récits et paroles concernant par exemple Salmān al-Fārisī, Abū al-Dardā’, Hudhayfa ibn

1 Voir en particulier les études de Melchert, notamment "The Transition from Asceticism to Mysticism" et Sviri, "Sufism: Reconsidering Terms, Definitions and Processes". 
al-Yamān, voire Ḥasan al-Bașrī lui-même, sont riches d'enseignements, mais difficiles à intégrer dans l'ordre de l'histoire. Un exemple éloquent est celui de Ḥasan al-Bașrī, dont la figure hagiographique a récemment été déconstruite par Suleiman A. Mourad ${ }^{2}$. Quoiqu'il en soit, on peut raisonnablement admettre que vers le viII ${ }^{\mathrm{e}}$ siècle, commença à apparaître l'idée d'une pluralité des niveaux de la foi. A une foi ordinaire, simple acquiescement (tașdīq) aux deux shahāda et au dogme commun, s'opposa une exigence personnelle de conformer sa vie entière au seul être, à la seule cause qui mérite le total don de soi : le service de Dieu. Une sorte d'élite spirituelle émergea parmi les croyants : ascètes, prédicateurs, fervents qui attirèrent rapidement beaucoup de croyants, qui discernaient en eux la réalisation d'un idéal de foi. En bref, se diffusa l'idée d'une alliance particulière, voire d'une amitié divine - walāya - accordée à ces personnes. Cette walāya avait vocation à prolonger la vertu du Prophète. Mais en quels termes? C'est la question posée ici. Que représente l'imitation du Prophète pour les premiers mystiques? Ils se sont posés comme héritiers des prophètes - mais en quoi consiste cet héritage ? En quoi se différencie-t-il, voire s'oppose-t-il au courant « traditionniste $»^{3}$ ? Bien sûr, on ne peut pas faire abstraction du fait que les sources sur ces premières générations de mystiques sont elles aussi bien tardives: $\mathrm{X}^{\mathrm{e}}$ et $\mathrm{XI}^{\mathrm{e}}$ siècles, pour celles que nous allons citer. Y recourir n'est pas une opération sans risque méthodologique. Notons toutefois que la mémoire transmise par la littérature hagiographique au sujet des plus anciens spirituels a gardé bien des traits archaïques. Par exemple, le lexique technique des expériences spirituelles ( $a h w a \bar{l} l, m a q \bar{a} m \bar{a} t$ etc) est peu détaillé, voire inexistant dans les notices consacrées à ces «anciens». A la place, nous lisons des énoncés directs, parfois paradoxaux, exprimés directement en termes coraniques.

Un point fondamental pour notre sujet réside dans la paucité des mentions de Muhammad chez ces mystiques anciens. Cela contraste avec les textes soufis plus récents, où la référence au modèle muhammadien est tout à fait explicite, comme nous le verrons infra avec le Kitāb al-luma' de Sarrāj. Ce point doit être interprété à la lumière des circonstances historiques. Au viII ${ }^{\mathrm{e}}$ siècle, le sunnisme n'existait pas encore de façon constituée. Ce n'est qu'au siècle suivant que les ahl al-sunna wa-al-jamāa se définirent comme majorité consensuelle dotée d'une doctrine cohérente et stable. Il s'agissait de lutter contre les affirmations des shīites revendiquant pour leurs Imams l'autorité religieuse absolue ; et des mu'tazilites, affirmant notamment la prééminence de la raison

2 Mourad, Early Islam between Myth and History: Hasan al-Bașrī.

3 Sur ce dernier point, voir Melchert, "The Piety of the Hadith Folk" et "Early Renunciants as Hadìth transmitters". 
comme outil exégétique. Dès lors, l'affirmation fondamentale de l'inerrance du Prophète, du caractère absolu du modèle qu'il offrait devint la colonne vertébrale de la pensée majoritaire sunnite. Mais au siècle précédent, la vision de ce modèle n'était pas l'horizon immédiat des premiers mystiques. Bien connue est la réplique de Rābía al-'Adawiyya (m. 185/8o1), interrogée sur son amour envers le prophète Muhammad, et qui répondit: «Je l'aime, mais mon amour du Créateur m'a détournée de l'amour de ses créatures $»^{4}$. Son cas n'est pas unique. L'accent était mis sur la première shahāda. Que représentait alors la seconde shahāda, ou l'idée de sunna, pour une perspective mystique?

Pour le cadre limité de ce chapitre, et pour ne pas se disperser sur des ouvrages d'intention trop hétérogène, notre propos se limitera à deux oeuvres choisies comme un simple échantillonnage : d'une part la Hilyat al-awliy $\bar{a}^{\prime}$ de Abū Nu'aym al-Iṣfahānī ${ }^{5}$, source considérable pour notre connaissance du soufisme ancien. Puis d'autre part, par contraste, nous aborderons le Kitāb al-luma d'Abū Nașr al-Sarrāj, pour renseigner un exposé sur les représentations plus récentes.

Abū Nu'aym (m. 430/1037) était lui-même un savant muhaddith de formation classique. Il représente une tradition tout à fait sunnite. Il a notamment rédigé un recueil de hadìth concernant les qualités du Prophète, le Dalāil al-nubuwwa, qui connut un vaste succès. La Hilyat al-awliya $\bar{a}^{3}$ est une véritable encyclopédie de spiritualité musulmane, fournissant 689 notices sur autant de personnalités religieuses, depuis les premiers Compagnons et Suivants jusqu'aux soufis contemporains de l'auteur, et incluant notamment les fondateurs d'écoles de droit (mais non Abū Ḥanīfa toutefois). Plus tard, Ibn al-Jawzī dénoncera cette composition comme une confusion, ou une récupération ${ }^{6}$. Tout en louant le propos général d'Abū Nu'aym al-Iṣfahānī, Ibn al-Jawzī critique l'attribution du soufisme à des personnes qui n'ont aucun rapport avec lui. Ibn al-Jawzī rappelle qu'il existe une différence entre le zuhd au sens strict - et toutes les personnes citées étaient bel et bien des zuhhäd - et le tașawwuf, qui est une école (madhhab) bien précise. Abū Nu'aym apporte en effet des citations de hadith à l'appui, mais de façon assez désordonnée, parfois douteuse? La conclusion de Ch. Melchert sur les sources d'Abū Nu'aym est que les sources (= les isnād-s) d'Abū Nu'aym sur les ascètes ne sont pas les mêmes que celles

4 'Attar, Le mémorial des saints, 92 ; cf. Masotta, "Les premiers ascètes en Islam", 449.

5 Ed. Beyrouth, Dār al-kutub al-ilmiyya, 1988, 10 vol. Voir Khoury, "Importance et authenticité des textes de Hilyat al-awliyā" ; Melchert, "Abū Nu'aym's Sources for Hilyat al-awliyā"”; Mojaddedi, The Biographical Tradition in Sufism, 41-67.

6 Șifat al-șafwa, 13: Iḍāfat al-tașawwuf ilā kibār al-sādāt (...) wa-laysa 'inda hāulā'i al-qawm khabar min al-tașawwuf.

7 Ce que lui reproche du reste Ibn al-Jawzī, Șifat al-șafiwa, 12. 
sur les soufis. La dernière partie de la Hilyat al-awliy $\bar{a}^{3}$, consacrée aux soufis, au sens strict, est selon lui assez mal organisée et comme plaquée assez artificiellement sur la précédente ${ }^{8}$. Mais la question est ailleurs. Il semble que le but de Abū Nu'aym n'était pas de montrer que tous les grands Anciens étaient des mystiques, mais qu'il existe une cohérence globale dans l'ensemble de la pensée spiritualité islamique autour de la notion d'amitié à Dieu (walāya). Chez lui, le modèle muḥammadien serait comme intériorisé dans les exemple vécus des grands saints. Ce qui conduit le propos d'Abū Nu'aym à certaines audaces. Ainsi, à propos du sujet qui nous occupe, mentionne-t-il une affirmation attribuée à Jacfar al-Ṣādiq : «Celui qui vit selon l'aspect extérieur de l'Envoyé est sunnī; celui qui vit selon la dimension intérieure de l'Envoyée est șūfì ${ }^{9}$. Une synthèse importante sur ce point a été apportée par Kabira Masotta-Naït Raïss dans une thèse récente sur la Hilya ${ }^{10}$. Elle développe l'idée de la sunna comme imitation intérieure du Prophète, à laquelle se conforment les ascètes stricto sensu comme les mystiques (soufis). Il s'agit d'atteindre, au-delà de la pratique extérieure, l'éveil d'une fitra qui permet le contact avec Dieu.

Nous allons prendre quelques exemples, parmi des dizaines, voire des centaines d'autres possibles. Il s'agit de trois grandes figures représentant trois générations : Mālik ibn Dīnār (m. vers 131/745), qui fréquenta Ḥasan al-Bașrī et marqua les premières formulations d'une expérience mystique ${ }^{11}$, 'Abd al-Wāhid ibn Zayd ( $m$. sans doute après $150 / 767$ ), qui enseigna un début de doctrine ${ }^{12}$, et Fuḍayl ibn 'Iyāạ (m. 803), dont l'influence fut particulièrement marquante ${ }^{13}$. Ces figures se sont toutes placées au sein du courant sunnite. Ainsi Abū Nu'aym

8 Melchert, "Abū Nu'aym's Sources for Hilyat al-awliyā".

9 Hilyat al-awliyā' I, 20-21: Man 'āsha fì zāhir al-rasül fa-huwa sunnī wa-man 'āsha fì bāțin al-rasūl fa-huwa șūfí. Ce à quoi Abū Nu'aym ajoute avec nuance: arāda Jaffar bi-bāțin al-rasūl akhlāqa-hu al-țāhira.

10 Masotta, "Les premiers ascètes en Islam", 408-31.

11 Masotta, "Les premiers ascètes en Islam", 134-37.

12 C'est du moins l'opinion de Massignon, "Essai sur les origines du lexique technique", 21314. 'Abd al-Wāḥid ibn Zayd aurait été disciple de Ḥasan: “... wa-kāna mimman yaṣhabu al-Hasan" (selon Sarrāj, Kitāb al-lumac, 45). Les dates semblent un peu compliquer les choses : le très jeune 'Abd al-Wāhiid aurait pu rencontrer Hasan à la fin de sa vie; mais il y a plutôt là l'indice d'une volonté d'établir des enchaînements d'enseignements initiatiques (voir Mourad, Early Islam between Myth and History, 100-101, sur la construction des isnād-s). Plus vraisemblablement, il aura été le disciple de Mālik ibn Dīnār. Voir aussi Masotta, "Les premiers ascètes en Islam", 140-41.

13 Jacqueline Chabbi a mené une enquête fouillée sur la biographie et les dires attribués à ce personnage illustre ("Fuḍayl ibn 'Iyāḍ, un précurseur du hanbalisme“, 331-345). Elle voit en lui un ascète réformiste, non un mystique au sens soufi du terme. Nous estimons toutefois que Fuḍayl représente précisément une figure de passage vers la mystique proprement dite. Voir aussi K. Masotta, “Les premiers ascètes en Islam”, 158-59. 
prête-t-il à Fuḍayl la déclaration : «Engage-toi dans la bonne vie - l'islam et la sunna $»^{14}$. On notera d'emblée la formulation inhabituelle: on s'attendrait au couple Coran/sunna ou islām/ìmān. Apparaît ici comme une suggestion de différenciation entre un islam représenté par l'adhésion au Coran, et une sunna dont les contours sont encore imprécis, mais qui en tout cas ne fait pas complètement corps avec la religion au sens usuel. Où situer alors la sunna du Prophète? On notera la rareté des références au Prophète dans les évocations de la vie ascétique et mystique de ces personnages. Si des hadïth sont cités, nous l'avons vu, l'exemple prophétique est peu invoqué. Bien sûr, il serait bien peu rigoureux de tirer une conclusion à partir d'un silence des textes. Tâchons alors de prendre un angle un peu décalé et demandons nous en quoi consistait la voie spirituelle de nos trois mystiques. Et alors, en quoi celle-ci reflèterait un modèle muhammadien.

Dans les trois cas, il s'agit d'ascètes. Leur voie est donc très marquée par la privation. Je me bornerai à quelques remarques.

1) La voie de nos ascètes était très axée sur la privation de nourriture. Il s'agissait de manger le moins possible, et le moins souvent possible. Le cas de Mālik ibn Dīnār est resté fameux ${ }^{15}$, Or l'exemple prophétique n'est pas du tout en jeu ici. Certes, la pureté rituelle de l'alimentation (et des vêtements, etc) était un point essentiel pour tous. Mais il est aisé de constater que leurs jeûnes dépassaient largement l'enseignement muhammadien tel qu'il sera fixé dans les hadìth canoniques. Ils relèvent plutôt d'une piété ascétique qui imprégnait toute l'époque de l'Antiquité tardive, d'un Zeitgeist qui n'était pas particulièrement islamique. On y retrouve une vision spiritualiste de l'homme et des rapports âme/corps, une conscience aiguë de l'imminence eschatologique, qui était partagée par bien des milieux chrétiens, gnostiques, ou manichéens.

2) De même, la valeur accordée au célibat est une tendance bien peu muhạmmadienne. Mālik Ibn Dīnār aurait affirmé : « L'homme ne devient un juste (șiddīq) que s'il laisse sa femme comme à l'état de veuvage, et va demeurer dans les décharges fréquentées par les chiens $»^{16}$. Lui-même semble être resté célibataire. Ce qui est à retenir, c'est sa radicalité dans le détachement. Or femme et famille impliquent des liens très exigeants. Il aurait répondu à quelqu'un qui lui demandait pourquoi il ne se mariait

14 Usluk al-hayāàt al-țayyiba, al-islām wa-al-sunna, Hilyat al-awliyā' $\bar{a}^{\prime} I I I, 99$.

15 Hilyat al-awliyā' II, 366-77, 369, 370.

16 Làyablughal-rajulmanzilat al-șiddīqìn ḥattāyatrukzawjatahu ka'annahā armala wa-ya’wī ilā mazābil al-kilāb, Hilyat al-awliyā' $\mathrm{II}, 359$. 
pas: «Si je le pouvais, je répudierais mon âme $»^{17}$. Mālik n'était pas le seul à avoir agi ainsi. Ibrāhīm ibn Adham a quitté sa famille après sa soudaine conversion ${ }^{18}$. Fuḍayl a laissé le souvenir du seul et unique sourire de sa vie - au moment de la mort de son fils ${ }^{19}$. Or Muhammad a vivement condamné, voire anathémisé ces attitudes. Il a réprouvé le célibat pour des causes religieuses ${ }^{20}$. Le sacrifice, l'ascèse suprême, c'était de se préparer au combat. Selon un hadīth célèbre rapporté par Ibn Hanbal : «Tout prophète a son monachisme (rahbāniyya); et la rahbāniyya de cette communauté est le combat au service de Dieu ${ }^{21}$. En fait, ce n'est que petit à petit que cette méfiance à l'égard de la vie conjugale a évolué dans les milieux piétistes; on en trouve d'ailleurs des traces dans des époques plus récentes.

3) Enfin se pose la question de la référence aux hadīth. Il arrive que des hadïth soient cités par nos ascètes dans le texte de la Hilyat al-awliy $\bar{a}$. Ils vont généralement dans un sens d'ascèse et de spiritualité. Ce qui nous amène à nous interroger sur la fonction de ces références. Fuḍayl avait lui-même acquis une véritable formation de muhaddith. Sulamī - qui, il est vrai, a tendance à vouloir faire de chaque grand soufi un transmetteur de hadith - mentionne dans sa notice sur Fudayl la transmission d'un hadīth de portée ascétique, sur le bénéfice de la souffrance pour les saints ${ }^{22}$. Selon Abū Nu'aym, Fuḍayl était d'ailleurs fiable en hadīth. Cependant, Abū Nu'aym nuance cette affirmation en précisant que la transmission des hadìth suscitait en lui une crainte révérencielle (kāna ... shadìd al-hayba li-l-hadìth) et du coup lui pesait beaucoup (kānayathqulu 'alayhi al-hadīth jiddan $)^{23}$. Le transmetteur d'un récit sur Fuḍayl, Isḥāq ibn Ibrāhīm, ajoutait: «Il me disait souvent qu'il préfèrerait que je lui demande un dirham plutôt que je lui demande des hadïth. Un jour, il me

Law istața'tu la-țallaqtu nafsī, Hilyat al-awliyā’ II, 365. Voir Benkheira, La maîtrise de la concupiscence.

18 Hilyat al-awliyä $\bar{a}^{\prime} \mathrm{II}, 368-69$.

19 Il aurait répondu à ceux qui l'interrogeait à ce sujet: “Dieu a aimé une chose, et j'ai aimé ce que Dieu a aimé”, Hilyat al-awliyā' viıI, 100.

20 Au verset coranique 5, 87: "Ô les croyants : ne déclarez pas illicites les bonnes choses que Dieu vous a rendues licites ..., les commentateurs donnent plusieurs noms de personnes tentées par l'ascèse en matière de nourriture, de sommeil, voire de femmes. Dans son tafsīr, Muqātil ibn Sulaymān cite : 'Alī, 'Umar, Ibn Mas'ūd, 'Ammār ibn Yāsir, 'Uthmān ibn Maẓ'ūn, al-Miqdād ibn al-Aswad, Abū Dharr, Salmān, Ḥudhayfa et d'autres. Muhammad a vivement condamné, anathémisé ces attitudes (voir Gilliot, "Le Coran avant le Coran", 165). Musnad v, 266, Xvi, 26. Cl. Gilliot, "Le Coran avant le Coran”, 167-75.

22 Țabaqāt al-șüfyya, 9.

23 Kāna șaḥị̣ al-ḥadīth șadūq al-lisān, Hilyat al-awlìyā'viıI, 86-87. 
dit qu'il lui serait plus agréable que je lui demande de l'argent (danānìr) plutôt que des hạdīth. Je lui répondis que s'il me transmettait des hadīth où je trouverais des bénéfices dont je suis privé, je préfèrerais cela à recevoir de lui le même nombre de dinars. Il me dit: "Tu es égaré (maftūn)! (...) Si on te présente de la nourriture et que tu jettes chaque bouchée que tu prends derrière ton dos, quand seras-tu rassasié ?" $»^{24}$. En d'autres termes, s'occuper de colliger des hadith les uns après les autres sans les mettre en pratique, revient à un profond gâchis spirituel.

Une distinction radicale semble exister entre la vraie sunna - intérieure, celle qui à la limite se transmet dans le silence du cœur - et la science mondaine du hadìth, celle qui ne sert à rien d'un point de vue spirituel ${ }^{25}$. On peut interpréter : en multipliant la diffusion des paroles du Prophète, on leur fait perdre leur efficace. Elles échappent à lâme, ne la nourrissent plus, au contraire. La même idée se retrouve chez Mālik Ibn Dīnār : le hadìth n'a d'utilité que s'il aide à la pratique spirituelle. Ses paraboles sont expressives : «J'ai lu dans un livre de Sagesse qu'il est pour toi sans utilité de savoir une science, puis de ne pas mettre en œuvre ce que tu sais. C'est comme un homme qui va ramasser du bois, rassemble un fagot qu'il ne peut soulever, et lui ajoute alors un autre $»^{26}$. Mālik Ibn Dīnār aurait transmis un certain nombre de hadīth notamment de Anas ibn Mālik. Leur contenu est éloquent: il vise souvent les mauvais sermonnaires qui disent et ne font pas, et ceux qui n'ont pas honte de leur tiédeur, laquelle est blasphématoire au fond ${ }^{27}$. Ce genre de diatribes semble anachronique par rapport à l'époque muhammadienne, mais il est significatif de l'opposition ultérieure entre ascètes et savants. Les réunions de muhaddithūn provoquaient chez Mālik Ibn Dīnār une sorte d'angoisse ; « Lorsque j'entends la voix des transmetteurs de hadìth, je suis pris par l'envie d'uriner, par terreur $»^{28}$.

Une autre explication de ces réticences à l'égard des hadith réside dans la prévalence accordée au Coran. Abū Nu'aym signale une réplique de Fuḍayl qui vit un homme (un muhaddith peut-on supposer) qui riait, et lui dit: «Veux-tu que je te transmette un hadìth bon (a-lä uhaddithuka hadìthan hasanan)? Oui, répondit l'autre. Fuḍayl récita "Ne te réjouis pas, Dieu naime pas ceux

\footnotetext{
24 Hilyat al-awliy $\bar{a}^{3}$ VIII, 86-87.

25 K. Masotta, "Les premiers ascètes en Islam", 426-29.

26 Hilyat al-awliya $\bar{a}$, II, 375.

27 Hilyat al-awliy ā’ II, 386. Dénonçant les corruptions de son époque, Mālik Ibn Dīnār cite toutefois aussi un hadīth remontant à Anas ibn Mālik demandant de ne pas prier contre les gouvernants, mais de prier Dieu pour les améliorer, Hilyat al-awliy $\bar{a}^{2}, \mathrm{II}, 388$.

Hilyat al-awliyä', VIII, 94, 95 .
} 
qui se réjouissent" ${ }^{29}$. Or il s'agit d'un verset du Coran, XxvirI 76 . Certes, le terme « hadith» est plurivoque, il ne désigne pas nécessairement une parole prophétique. La réplique mérite néanmoins réflexion. Le hadīth n'a au fond de valeur que s'il vient prolonger la parole coranique. Le Coran est la base du chemin spirituel. La méditation profondément coranique de Mālik est évoquée par Sarrāj ${ }^{30}$ : «Quelqu'un a dit - je crois que c'est Mālik Ibn Dīnār : J'ai mâché le Coran pendant vingt ans, puis j'ai pris plaisir à sa récitation pendant vingt ans $»^{31}$. Et de fait, Fuḍayl ibn 'Iyāạ professait quant à lui explicitement la prévalence du Coran sur la hadìth. Ainsi sa parole : «Si j'avais reçu dès mon début sur la voie la grâce de la compréhension du Coran et des méditations de nuit que j'ai acquise maintenant, je n'aurais pas écrit un seul hadīth (mā katabtu hadìthan qattt), et je me serais consacré au seul Coran ${ }^{32}$. Nous touchons ici un point fondamental de l'évolution de la spiritualité musulmane. Il ne s'agit pas d'une appréciation sur le hadìth en tant que tel, ni d'une dévalorisation du modèle prophétique. Nous avons ici plutôt une affirmation précise de la fonction du saint, investi directement par la grâce divine. Le saint est « porteur du Coran », c'est-à-dire, des sens profonds du Coran. C'est cela sa mission, sa fonction, sa grâce. Le saint est porteur du message divin, directement. Et pour être plus précis : ce message coranique n’a pas à être médiatisé par un hadith qui ne fait que creuser une distance supplémentaire entre la conscience du croyant et la source divine.

Ce rôle est illustré par un certain nombre de hadìth qudsī que Fuḍayl semble sortir de sa propre autorité. Leur contenu mystique n'est pas indifférent: la nuit, Dieu descend du ciel et cherche ceux de ses fidèles qui ne dorment pas. Il s'adresse à ces veilleurs qui sont ses vrais amants, Il Se laisse contempler, manifeste sa présence et leur promet le Paradis ${ }^{33}$. L'absence d'isnād à propos de ces paroles est-elle un simple effet d'habitude? Ou bien Fuḍayl s'attribue-t-il une autorité d'inspiré divin? Ou s'agit-il simplement d'un artifice littéraire? Un autre hadīth qudsī, fort connu, souligne également ce rôle d'intermédiaire prophétique des saints. Il apparaît cité par 'Abd al-Wāḥid ibn Zayd, lequel le fait remonter à Ḥasan al-Bașrī, et il commence par : «Lorsque mon serviteur est sans cesse préoccupé par Moi, Je mets son bonheur (naimahu) et son plaisir dans mon évocation (dhikrī), et lorsque Je mets son bonheur et son plaisir

29 Hilyat al-awliyā’, viII, 108. Le verset est adressé à Qārūn et à ses gens, ce qui précise l'intention de Fudiayl dans sa citation.

30 Kitāb al-luma, 67 .

31 Madaghtu al-Qur'ān 'ishrīna sana, thumma tana"amtu bi-tilāwati-hi 'ishrīna sana; également Hilyat al-awliya $\bar{a}$, II 358, 378.

32 Abū Ṭālib al-Makkī, Qūt al-qulūb, I, 76.

33 Hilyat al-awliya $\bar{a}$, vııI, 92-93, 99-101. 
dans mon évocation, il M'aime avec passion et Je l'aime avec passion ('ashiqan̄ wa-'ashiqtuhu). Et lorsqu' il M'aime avec passion et que Je l'aime avec passion, Je lève le voile entre Moi et lui, et Je deviens un signe devant ses yeux ; et il n'est pas distrait quand les autres hommes sont distraits. Ceux-là, leur parole est la parole des prophètes $»^{34}$. Ces dernières paroles, plus que la mention de l'amour passionnel, soulignent la position des mystiques ${ }^{35}$.

Dès lors nous pouvons nous demander: dans quel domaine précis les mystiques situent-ils l'autorité prophétique muhammadienne? Comment et par qui cette autorité est-elle transmise depuis sa mort? Ce lourd problème théologique et politique, soulevé par les kharédjites et les shīites, contient en germe une bonne partie de la théologie du sunnisme. Nos anciens mystiques n'intervenaient qu'occasionnellement dans les questions politiques. Leur vision concernait une dimension plus ésotérique du déroulement historique de la umma. Ainsi, Mālik Ibn Dīnār exprime dans une remarque cinglante une contestation de la situation issue de la « Grande Discorde », typique des ascètes zuhhād de cette génération. Pour lui, les musulmans auraient agi comme les chrétiens après la mort de Jésus : « Nous savons que lorsque Jésus fils de Marie a été envoyé, il a renversé l'ordre du monde (al-dunya $)$. Après lui, les gens l'ont remis en place; jusqu'à ce que Muhammad soit envoyé, et renverse l'ordre du monde. Après lui, nous l'avons redressé en l'état » ${ }^{36}$. Mais alors, qui redressera la situation à présent? Qui va réhabiliter l'ordre prophétique muhammadien? Le futur sera redoutable en effet, car la fin des temps est déjà engagée. Lorsque viendra l'Heure, les croyants découvriront que leurs savants, leurs chefs, étaient en réalité des pervers, selon Mālik Ibn Dīnār : «A la fin des Temps, les vents et les ténèbres terrifieront les gens qui iront trouver leurs savants ('ulamāuhum); et ils les trouveront métamorphosés sous des formes monstrueuses ( fa-yajidūnahum qad musikhū) ${ }^{37}$. Cette allusion au maskh est évidemment d'une lourde portée, car elle fait allusion à la transformation des damnés. Il y a là une terrible dénonciation de la responsabilité des oulémas.

De nombreuses citations en ce sens sont à mettre au dossier de la lutte verbale entre les mystiques et les juristes ou muhaddithūn. A un homme qui disait que les savants étaient les héritiers des prophètes, Fuḍayl répondit : « Les sages

34 Hilyat al-awliy $\bar{a}^{\prime}, \mathrm{vI}, 165,1.7$. Ce hadīth ressemble bien sūr dans sa composition à celui dit "des nawāfil". Abū Nu'aym juge toutefois avec réserve la qualité de ce hadīth mursal, d'autant que la réputation de 'Abd al-Wāḥid dans le domaine aurait été faible.

36 Hilyat al-awliya $\bar{a}, \mathrm{II}, 381$.

37 Hilyat al-awliy $\vec{a}$, II, 382 ; on trouve une attitude analogue chez Fuḍayl, Hilyat al-awliy $\vec{a}$, vIII, 92, 100. 
(al-hukamä) sont les héritiers des prophètes $»^{38}$. Quand on parle de «lutte », il ne s'agit pas forcément de discuter de politique, ou de prestige religieux. Il ne s'agit pas non plus de remettre en cause le rôle des règles de droit. Il s'agit plutôt d'une attitude à la fois plus profonde et plus insaisissable : qu'est-ce qui fait l'essentiel de la foi ? Fondamentalement, qu'est-ce qui est demandé à l'homme croyant, à la communauté des musulmans? Quel est le sens à donner au verbe « obéir » à Dieu ? Et dès lors, qui est le vrai croyant, au sens plein ? C'est là où se situe la césure entre les deux attitudes. Fuḍayl affirme: celui qui n'incorpore pas complètement son rapport au Dieu vivant dans sa propre vie, qui ne quitte pas tout autre désir que d'obéir à Dieu, ne peut être guidé. Du coup, qui suivre, qui est le guide ? Une chose est sûre, ce ne sont pas les 'ulamä' officiels. Les savants mondains sont aux yeux de Fuḍayl comme des « renégats ». Fuḍayl pourfend avec violence les așhāb bid'a. Nombreuses sont les citations sur le danger des bid'as, sur le fait qu'il ne faut pas fréquenter ces gens, les éviter complètement. Plus, il faut les haïr, les maudire, ils détruisent l'islam ${ }^{39}$. Mais qui pointe la critique de Fuḍayl exactement? En quoi s'opposent-ils à la sunna, et que représente en fait l'idée de sunn $a^{40}$ ? Sont-ce les premiers mutazilites qui sont visés? Peut-être. Mais il est loisible d'identifier de façon plus radicale encore les bid'as que dénonce Fuḍayl, avec ces compromissions avec «le monde ». Nous sommes ici dans une perspective spirituelle, mystique, non théologique ou juridique. On est en droit de comprendre: le vrai musulman recherche la Sagesse, c'est là son orientation primitive, celle que montrait l'islam primitif, le Coran. La bid'a, c'est ce qui en éloigne. Autrement dit, la bid'a va bien au-delà de doctrines "nouvelles" ; elle représente tout ce qui fait dévier de l'intention première, du service exclusif de Dieu. Or celui qui se confie aux hadìth, transmis de façon purement «académique», dévie de cette manière, aussi paradoxal que cela puisse paraître. Au lieu de se tenir ici et maintenant dans la présence du Dieu vivant, il se crée un espace religieux d'où la divine présence se trouve mise à l'écart, voire absente.

On pourrait aboutir au point suivant, qui sera une première conclusion: l'imitation du Prophète chez le walī consiste précisément à ne pas se mimétiser à lui. Il s'agira plutôt d'actualiser en soi-même le hă $l$ prophétique, au lieu et au moment précis où vit le saint. Il s'agit de faire passer en acte tout ce qui est $\mathrm{su}^{41}$. Ceci suppose une totale disponibilité à la grâce divine dans l'instant, une

$38 \quad$ Hilyat al-awliy $\bar{a}$, VIII, 92.

39 Hilyat al-awliy $\bar{a}$, VIII, 103-4, 108. De nombreuses autres citations sont apportées par J. Chabbi dans son article cité supra "Fuḍayl ibn 'Iyāọ, un précurseur du hanbalisme".

40 Hilyat al-awliya $\bar{a}^{3}, \mathrm{VIII}, 104$.

41 K. Masotta, "Les premiers ascètes en Islam", 404-5. 
complète orientation de l'esprit vers Dieu à l'exclusion de toute autre science. Cette position sera explicitée par les théoriciens ultérieurs.

Les auteurs soufis plus tardifs ont explicité et commenté cette idée de sunna prophétique mystique. Le Kitāb al-luma d'al-Sarrāj en particulier nous fournit un exposé systématique, qui correspond à l'essor du soufisme proprement sunnite $^{42}$. Dans une importante introduction, il commence en effet par situer le rôle du saint, du șūfı au sens plein, comme véritable héritier muhammadien, de manière plus profonde et plus légitime que le juriste ou le muhaddith. A la différence des mystiques évoqués plus haut, la référence muhammadienne est donc appuyée. Mais de quel «prophète Muhammad » exactement le soufi est-il l'héritier, quel est l'aspect de la prophétie qui est mis en avant? Dans le Kitāb al-luma', un chapitre important est intitulé "Livre de l'imitation (al-uswa wa-al-iqtidā') de l'Envoyé" ${ }^{33}$. En effet, les soufis suivent la voie de Muhammad. Sarrāj rappelle la nécessité absolue de cette imitation, fondée d'après lui sur une série de versets coraniques. Un verset en particulier fait autorité, Coran 3, 31: "Dis : «Si vous aimez vraiment Dieu, suivez-moi, Dieu vous aimera alors et vous pardonnera vos péchés. Dieu est Pardonneur et Miséricordieux ». Il est impossible de prétendre aimer Dieu, suivre le Coran sans suivre également la sunna du Prophète telle qu'elle est formulée dans les hadith sûrement établis. Il existe une harmonie, une hiérarchie, une union liant ainsi l'amour de Dieu aux hommes. Ceci est évidemment valable pour tous les musulmans. Mais plus particulièrement pour les soufis, souligne Sarrāj ${ }^{44}$. La sainteté, pour Sarrāj, peut se concevoir comme une "muhammadisation" de la personne du soufi. De quelle imitation s'agit-il au juste ? Sarrāj établit une gradation dans l'imitation soufie du Prophète :1) suivre la sunna, pour le commun. C'est l'imitation à laquelle tout musulman est invité à se conformer. 2) imiter les règles de vie, les $\bar{a} d \bar{a} b$ du Prophète, pour les pratiquants exigeants, allant jusque dans les détails de l'imitation, dans l'ensemble des rapports sociaux notamment ; 3) imiter ses $a k h l a ̄ q$, pour ceux qui veulent lui ressembler intérieurement en observant les mêmes vertus morales. Enfin, par l'adhésion complète à cette pratique et à son intention, certains parviennent au niveau 4) de l'imitation des aḥwāl du Prophète, de ses états spirituels, dans son cheminement mystique. Par cette imitation, ils peuvent atteindre 5) ses vérités ultimes (haqā̄iquhu). C'est ici le point ultime, final, le propos central de Sarrāj ${ }^{45}$.

42 Kitāb al-luma ; voir aussi la traduction allemande par R. Gramlich, Schlaglichter über das Sufitum, Stuttgart, Franz Steiner Verlag, 199o, riche en notes et références.

43 Kitāb al-luma', 130.

44 Qui donne une vibrante évocation de la grandeur de cette imitation du Prophète (Kitāb al-luma, 133).

45 Kitāb al-luma', 143. 
Ceci dit, on ne peut comprendre où Sarrāj veut en venir si on ne suit pas la description qu'il trace des vertus concrètes du Prophète. Sarrāj énumère les qualités du Prophète que les soufis imitent. Il commence par la pauvreté, et y insiste très fortement. Ceci doit nous interroger : il existe entre l'idée même de "possession" et la voie mystique une barrière. Sarrāj commence par noter que Muhammad choisit d'être un prophète-serviteur "qui parfois est rassasié et parfois a faim", non un prophète-roi, sur le conseil de Gabriel ${ }^{46}$. Il aurait pourtant pu le devenir, à l'instar de David ou Salomon. Par ailleurs, Muhammad ne conservait aucune nourriture pour le lendemain. C'est toute la question de la remise à la providence divine, du tawakkul, qui appartient à des débats assez vifs au II et III ${ }^{\mathrm{e}}$ siècle $\mathrm{AH}^{47}$. Muhammad s'habillait de laine, poursuit Sarrāj. Autres signes de pauvreté : il montait sur un âne, trayait les chèvres, recousait ses sandales et son vêtement - il n'en possédait qu'un - et balayait le sol de sa maison. Parfois, il n'avait que des dattes ou de l'eau à manger, même pas de pain, pendant un ou deux mois. Il dut s'attacher une pierre sur le ventre pour moins sentir la faim. Comme les autres prophètes, il ne laissa aucun héritage. Muhammad détestait la richesse. Ceci par choix, car Dieu aurait pu lui fournir des montagnes d'or ${ }^{48}$. Bref, en tout point il valorisait positivement la pauvreté49. D'ailleurs, il aimait la pauvreté et les pauvres. Sarrāj cite le hadīth: «Ô mon Dieu, fais-moi vivre pauvre, fais-moi mourir pauvre, ressuscite-moi parmi le groupe des pauvres $»^{50}$.

Certes, tout ceci entre en contradiction avec bien d'autres hadīth concernant la personne du Prophète. Nous avons ici bien sûr affaire à une «stratégie hagiographique ». C'est en ce sens que Sarrāj fait une remarque à propos du hadith connu: «Trois choses mont été données à aimer dans votre monde, hubbiba ilayya min dunyā-kum thalāth ... ». On pourrait croire que Muhammad était attaché aux belles choses de ce monde, en l'occurrence les femmes et les parfums. Mais Sarrāj pointe la formulation choisie par lui « votre bas-monde », laquelle indique que Muhammad lui-même s'en excluait. Muhammad vivait dans le monde, mais il n'appartenait pas à ce monde ${ }^{51}$. La remarque est essentielle, on le comprend. Elle détermine pour une bonne part l'attitude du soufisme classique : détachement, mais non ascèse trop extrême. C'est un point de différence, voire de rupture avec les ascètes dont nous venons de parler. D'autres

\footnotetext{
46 Kitāb al-luma, 134. Le hadīth apparaît dans le Musnad de Ibn Ḥanbal.

47 Kitāb al-luma', 134-35. Le hadīth est cité chez Tirmidhī et Ibn Ḥanbal.

48 Kitāb al-lumai, 134 .

49 Kitāb al-luma', 134-35, 136, 127 ; le hadīth est cité par Ibn Hanbal.

50 Allāhumma, ahyinī miskīnan wa-amitnī miskīnan wa-ḥshurnī fì zumrat al-masākīn, cité chez Ibn Māja et Tirmidhī.

$5^{1} \quad$ Kitāb al-lumac 138 .
} 
ḩadïth vont affirmer que Muḥammad aimait le commerce, les beaux habits, les parfums etc. Sarrāj y fait allusion ${ }^{52}$. Pour lui, comme pour toute une partie de la tradition sunnite, c'était pour que son exemple soit plus facile à suivre par les musulmans qu'il proclamait cela. Sinon, l'islam n'aurait pas été praticable, et les passions auraient finalement dominé les croyants. Mais, affirme-t-il, les prophètes sont tous complètement indépendants face aux avoirs matériels. On oscille toujours entre l'image terrestre et la référence céleste des prophètes. Inutile de dire que cet avis de Sarrāj ne s'appuie que sur sa propre conviction, mais celle-ci est largement partagée en milieu soufi. Notons que pour Sarrāj, Muhammad aurait eu toutes les qualités, même contradictoires. Il était d'un naturel souriant, sans s'esclaffer ${ }^{53}$. Mais, selon Sarrāj, il était aussi toujours triste et préoccupé : de sa poitrine sortait un bouillonnement comme celui d'une marmite ${ }^{54}$. Là aussi, le paradoxe s'explique par la "complétude" nécessaire du Prophète comme Homme Parfait. Cette manière soufie de suivre le Prophète, de l'imiter, est une voie vers les plus hautes connaissances. Sarrāj explique qu'à ceux qui ont suivi le Coran et la sunna dans la rectitude s'ouvrent des portes nouvelles, d'une nouvelle science ('ilm mā lam ya lamühu).

Nous voyons dans les considérations de Sarrāj à la fois une continuité et des ruptures avec les ascètes des premiers siècles. Une continuité : il s'agit de faire en sorte de tout consacrer à Dieu sans aucune réserve ni aucun partage. Mais pour avoir accès à Dieu, il importe de se conformer à l'état intérieur du prophète Muhammad - ce dont les anciens mystiques ne parlaient guère. Bien sûr, le Prophète n'est pas divin en lui-même. La rencontre avec la présence divine ne peut avoir lieu que par une grâce venant de Dieu. Mais selon Sarrāj, cette expérience surnaturelle ne peut avoir lieu en-dehors d'un cadre naturel, humain, qui est celui de l'exemple prophétique. Ce passage de l'humain vers le divin peut être résumé par une citation que Sarrāj fait de Dhū l-Nūn à qui l'on demandait comment il avait connu Dieu : « J'ai connu Dieu par Dieu, et j'ai connu ce qui n'est pas Dieu par l'Envoyé de Dieu » 55 .

Nous pouvons conclure ce bref exposé en situant le débat dans l'ensemble de la vision sunnite de la foi. Revenons à l'introduction de la Șifat al-șafwa par Ibn al-Jawzī. Ibn al-Jawzī dénonce l'absence dans l'ouvrage d'Abū Nu'aym de la mention du premier des zuhhād, à savoir Muhammad. Ibn al-Jawzī qualifie Muhammad de «seigneur des ascètes, chef de tous, modèle de la création (...)

$52 \quad$ Kitāb al-luma, $141-43$.

53 Cependant d'autres ḥadìth cités par Bukhārī affirment que lorsqu'il riait, "on voyait ses molaires".

54 Kitāb al-lumac, 139.

55 Araftu Allāh bi-llāh, wa-'araftu mā siwā Allāh bi-rasūl Allāh, Kitāb al-luma', 45. 
celui dont la voie doit être suivie et l'état doit être imité ${ }^{56}$. La précédente critique qu'il adressait à Abū Nu'aym était la confusion entre ascèse/zuhd et mystique/tașawwuf. Le tașawwuf représente pour Ibn al-Jawzī une simple école (madhhab) - et il renvoie pour les distinctions particulières à son Talbīs Iblīs. Cette remarque nous permet de situer les limites externes que le sunnisme en général a donné au soufisme. Le soufisme n'est pas condamné, il peut même être loué sous bien des rapports. Mais, contrairement à ce qu'affirmait Sarrāj, il ne représente qu'une discipline parmi d'autres dans le dispositif religieux de l'islam, il n'est pas l'héritier direct et principal de la prophétie. Au fil des siècles s'est produit un phénomène central : la consolidation, l'expression ouverte de l'intermédiation du Prophète. Mais intermédiaire dans quel domaine exactement, et à quelle fin ? Entre qui et qui ? Chaque courant a pu discerner sa propre épiphanie prophétique, selon la pluralité doctrinale admise à l'époque classique de l'islam.

\section{Bibliographie}

\section{Sources}

Abū Nu'aym al-Ișbahānī, Hiilyat al-awliyā’’ wa-țabaqāt al-asfiyā', Beirut, Dār al-kutub al-ilmiyya, 1988.

Abū Ṭālib al-Makkī, Qūt al-qulūb, Beirut, Dār al-kutub al-'ilmiyya, 1997.

'Attar, F. D. Le mémorial des saints, Paris, Seuil, 1976.

Ibn al-Jawzī, Sifat al-șafwa, Alexandria, Dār Ibn Khaldūn, 1994, 2 vol.

Sarrāj, Kitāb al-luma', éd. 'AḤ. Maḥmūd et T. 'AB. Surūr, Cairo, Dār al-kutub al-ḥadītha, 1960; voir aussi la traduction allemande par R. Gramlich, Schlaglichter über das Sufitum, Stuttgart, Franz Steiner Verlag, 1990.

Sulamī, A. 'A. al-R. al-. Ṭabaqāt al-șüfyyya, éd. FD. Sirriyeh, Cairo, Maktabat al-Khānjī, 1986.

\section{Études}

Benkheira, M. H. La maîtrise de la concupiscence - Mariage, célibat et continence sexuelle en Islam, des origines au Xe-XVIe siècle, Paris, Vrin, 2017.

Chabbi, J. "Fuḍayl ibn 'Iyāḍ, un précurseur du hanbalisme", BEO 30 (1978), p.331-345.

Gilliot, C. "Le Coran avant le Coran - Quelques réflexions sur le syncrétisme religieux en Arabie centrale", dans M. Azaiez et S. Mervin, ed. Le Coran - Nouvelles approches, Paris, CNRs Éditions, $145-87$.

$5^{6} \quad$ Sayyid al-zuhhād wa-imām al-kull wa qudwat al-khalq (...) fa-innahu al-muttaba'țarīquhu al-muqtadā bi-hạlihi, Șifat al-șafwa I, 15 . 
Khoury, R. G. "Importance et authenticité des textes de Hilyat al-awliyā' wa-țabaqāt al-așfiy à' d'Abū Nu'aym al-Iṣbahānī (336-43o/948-1038)", Studia Islamica, 46 (1977), 73-113.

Masotta, K. "Les premiers ascètes en Islam d'après la Hilyat al-awliyā' d'Abū Nu'aym Entre zuhd et tasawwuf: l'émergence du saint", thèse E PHE, Paris 2017.

Massignon, Essai sur les origines du lexique technique de la mystique musulmane, Paris, Cerf, 1999.

Melchert, Ch. "Abū Nu'aym's Sources for Hilyat al-awliyä), Sufi and Traditionist", dans G. Gobillot et J.-J. Thibon, eds. Les maîtres soufis et leurs disciples $-I I I^{e}-V^{e}$ siècles de l'hégire $\left(I X^{e}-X I^{e} s\right.$. ), Beirut, Ifpo, 2012, 145-159.

Melchert, Ch. "Early Renunciants as Hadīth transmitters", The Muslim World, 92 (2007), 407-418.

Melchert, Ch. "The Piety of the Hadith Folk", International Journal of Middle East Studies, 34/3 (2002), 425-439.

Melchert, Ch. "The Transition from Asceticism to Mysticism at the Middle of the Ninth Century C.E.", Studia Islamica, 83 (1996), 51-70.

Mojaddedi, J. The Biographical Tradition in Sufism: The Tabaqāt Genre from Sulamì to Jāmī, Richmond, Curzon, 2001.

Mourad, S. Early Islam between Myth and History: Hasan al-Bașrī and the Formation of his Legacy in Classical Islamic Scholarship, Brill, 2006.

Sviri, S. "Sufism: Reconsidering Terms, Definitions and Processes in the Formative Period of Islamic Thought", dans G. Gobillot et J.-J. Thibon, eds. Les maîtres soufis et leurs disciples - III ${ }^{e} V^{e}$ siècles de l'hégire $\left(I X^{e}-X I^{e} s\right.$. $)$, Beirut, Ifpo, 2012, 17-34. 